\title{
UNA ESCULTURA TEQUITQUI EN MONTERREY
}

$\mathbf{P} \mathbf{R}$

\author{
JUSTINO FERNANDEZ
}

I AS investigaciones sobre nuestra escultura colonial han de seguir ofre$\perp$ ciendo sorpresas por mucho tiempo, todo el que tardemos en conocer bien el legado artístico que nos dejaron los tres siglos de dominación española. Afơrtunadamente crece día a día el interés por esta clase de estudios y en farticular por la escultura de ese periodo, que, como certeramente apunta Moreno Villa' no se le ha dado aún la atención que merece.

Corno una pequeña pero interesante contribuciớn al tema, damos ahora a conocer una extraordinaria escultura monolítica, con la cual topamos, ${ }^{2}$

1 José Moreno Villa. La Excultura Colonial Mexicane. Edit. El Colegio de México, 1942.

2 Don Manuel Tonsaint, Salvador Tousao y el que estas lineas excribe estuvimos en Monterrey, invitados por la Univerridad neolonente para dar una erie de conferencias obre arte, a prineipios de 1944. Fut en ena ocasión que visitamos las ruinas del Obispado. Las fotografias que aqui a poblican fueron tomadas por Sal. vador Tosano. 
por así decirlo, al visitar la iglesia, hoy dia en estado de ruina, que se encuentra en la loma del Obispado en la ciudad norteña de Monterrey, N. L. En el corredor del patio que forman las crujías de la construcción contigua a la iglesia, puede verse la escultura que ocupa nuestra atención, acerca de la cual, en una inscripción, se lee lo siguiente: Esta antigua y deteriorada escultura fué encontrada al hacer excaraciones en donde estuvo el templo de San Francisco, en esta ciudad de Monterrey, al lado Oriente de la prolongación de la calle de Zaragoza, el 19 de agosto de 1932, traida a este sitio el 25 del mismo mes y año; no tiene historia conocida, se conserva por lo que es: gestiones del Dr. Amado Fernándes. Efectivamente, lo anterior y la escultura misma son los únicos datos que tenemos y, por lo tanto, después de leído el letrero, cabe preguntarse que si se conserva por lo que es, ¿qué es, pues, la escultura aludida?

Los autos de fundación de la ciudad de Nuestra Señora de Monterrey están fechados el 20 de septiembre de $1596 .^{\circ}$ El primer convento en todo el Nuevo Reino de León fué franciscano y se fundó el año de 1600, cuando fué allá, de México, el Padre Ciprián de Acevedo, con soldados y algunos animales de campo y quien pidió religiosos de Nuestro Padre San Francisco para el convento, que llamó San Francisco de San Andrés y de los cuales los primeros fueron Fray Lorenzo González, el viejo, y Fray Martín de Altamira, pronto muerto a manos de los indios.

Asi pues, la construcción misma del convento debe haberse llevado a cabo en los primeros años del siglo xvII y de esa fecha ha de ser, posiblemente, la ejecución de la escultura de que ahora tratamos y que, por la estrella que muestra en la frente, que más bien parece uná flor, quizá represente la imagen de Santo Domingo; su altura es, aproximadamente de un metro cuarenta centímetros y, por supuesto, es monolítica.

La sobriedad, el primitivismo, digamos, o la tosquedad con que está hecha, le prestan un carăcter singular, que hace pensar, por un lado, en las esculturas románicas y por otro en las indígenas precortesianas, si bien, es indudable que participa a la vez de un concepto occidental y de otro indigena. Esto que es lo que da carácter a tantas esculturas del siglo XVI, ha sido llamado por Moreno Villa lo tequitqui o mudéjar mexicano ${ }^{6}$ para

3 Vito Alessio Robles. Monterrey en la Historia y en la Leyenda. Edit. Antigua Lib. Robredo de José Porrúa e Hijos. Méx, 1936, p. il 26.

4 Lic. Santiago Roel. Nuevo León. Apuntes Históricos. T. I., pág. 27

5 Alessio Robles. op. cit., ṕ́g. 131 y siguientes

6 Op. cit., pág. 16. 


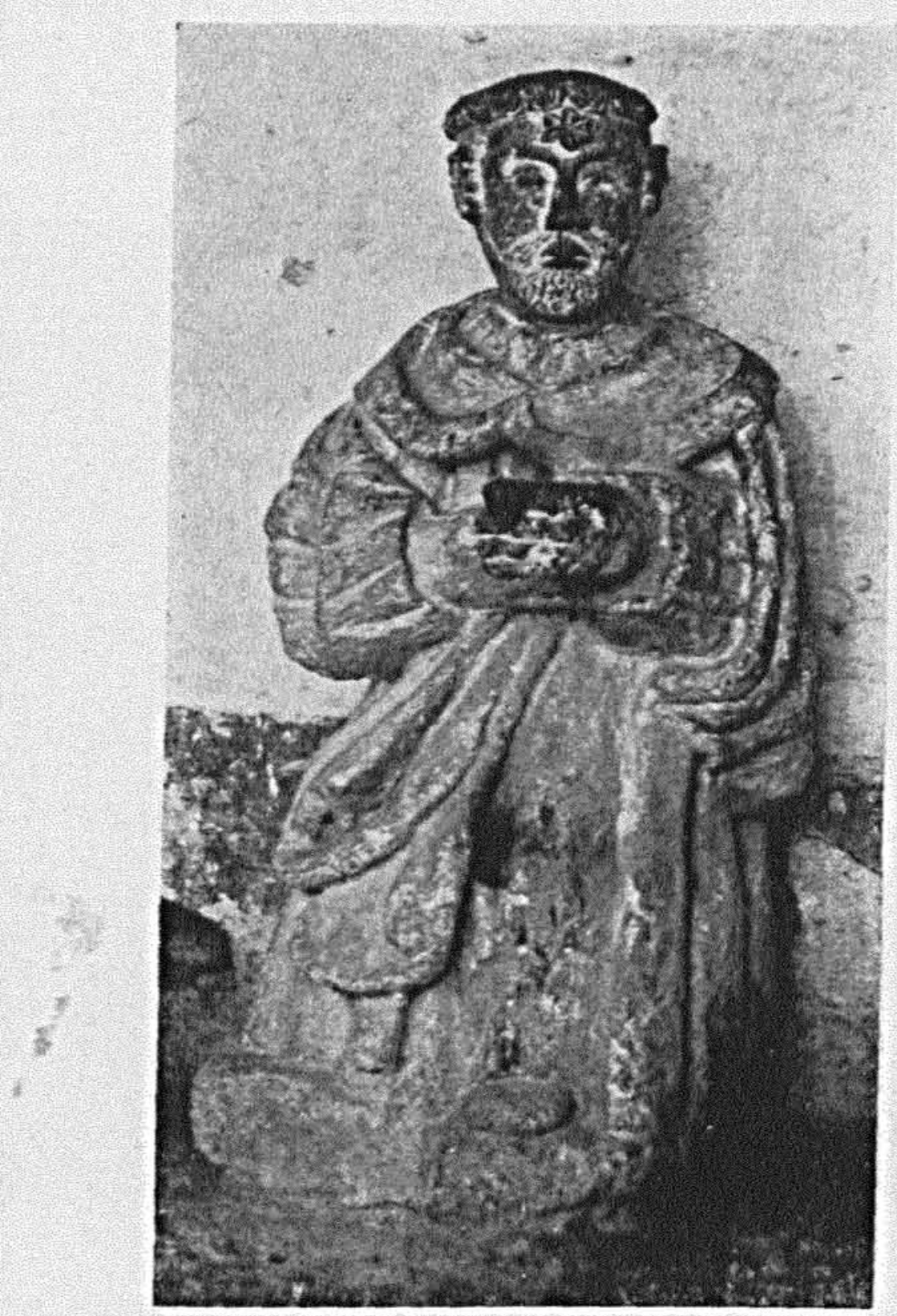

Fig. 1. Santo Domingo. Escultura de principios deI siglo XVII. Monterrey.

(Foto Salvador Toscano.) 
DOI: http://dx.doi.org/10.22201/iie.18703062e.1945.12.386

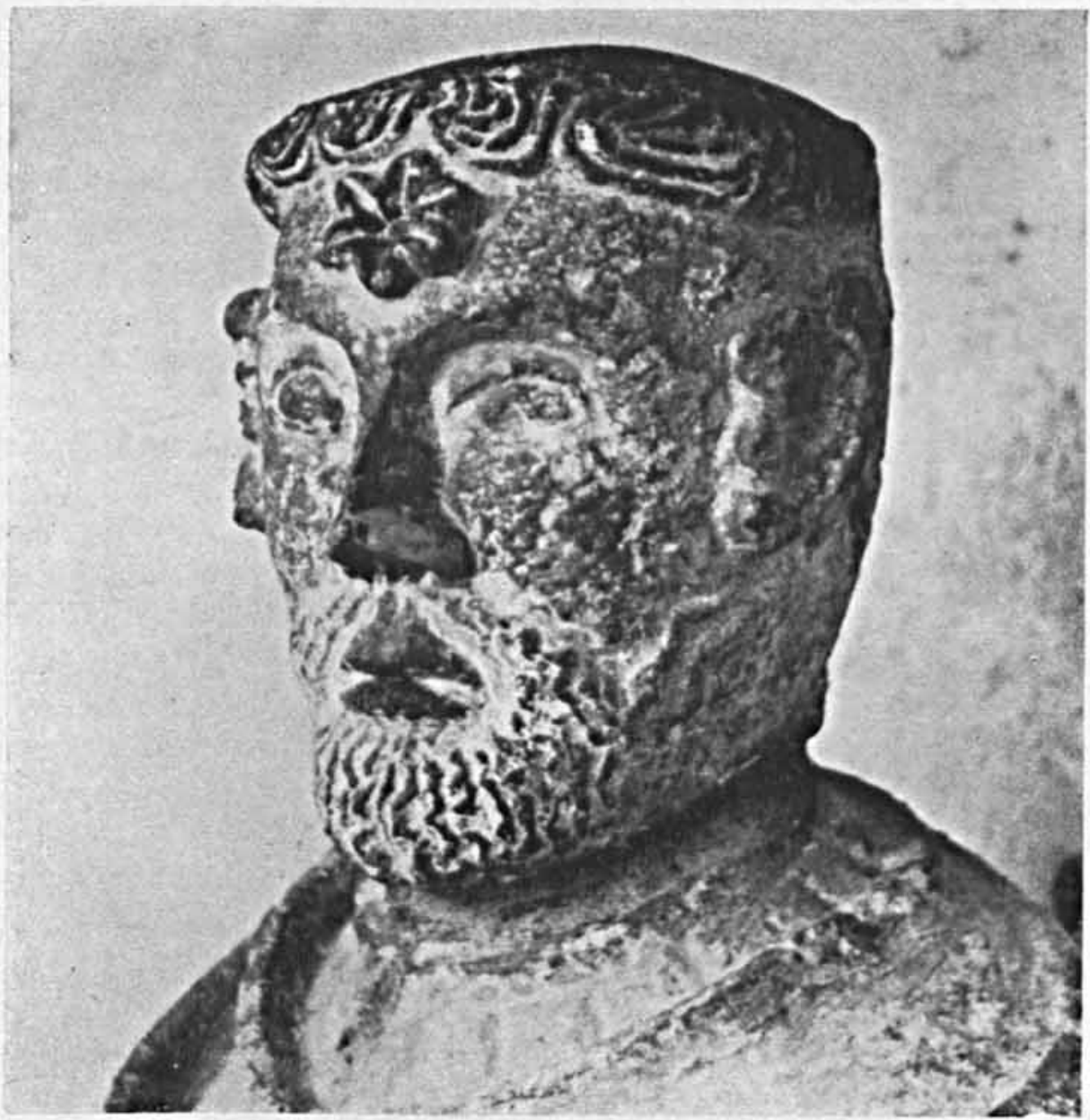

Fig. 2. Detalle del anterior. 
dar un término propio al arte indigena tributario del español, o más ampliamente, del occidental; esta escultura es pues arte tequitqui, si hemos de aceptar el término, o simplemente en ella se expresa sin duda un sentido escultórico indigena; veamos por ejemplo la forma en que el artista ha estilizado el pelo y recordemos la representación indígena del agua; la estrella o flor que luce en la frente el fraile es también de estilización indigena y en general el corte de la piedra, los amplios y simplificados pliegues del hábito, todo acusa la mano de un artista indígena que supo dar a su obra una vigorosa expresión.

Por sus formas, a primera vista, nadie dudaría de que se trata de una escultura del siglo XVT, pero por la fecha de la fundación del convento es indudable que pertenece al siglo xvir; como en tantos otros casos se trata de supervivencias de formas que se prolongan independientemente de la estricta cronología, por lo cual esta escultura, si bien ejecutada en el xvir, puede decirse de ella que por sus formas es del xv.

Sin duda hay una diferencia apreciable entre el cuerpo de la imagen y la cabeza, pues en ésta el artista tuvọ la intención de hacer una expresión más naturalista, a pesar de las estilizaciones, que en el hábito, o en la tosca mano. Es precisamente ese refinado constraste uno de los valores que tiene esta impresionante $y$ por todos conceptos extraordinaria escultura, que contribuye a demostrar cómo en la Nueva España persiste esta influencia o carácter indígena expresado con naturalidad en el arte cristiano, dándole una calidad sui géneris.

Por último, hay que hacer notar que esta escultura debe haber formado parte de la fachada o de alguna otra de la construcción del convento y no es una imagen aislada, dedicada al culto. 